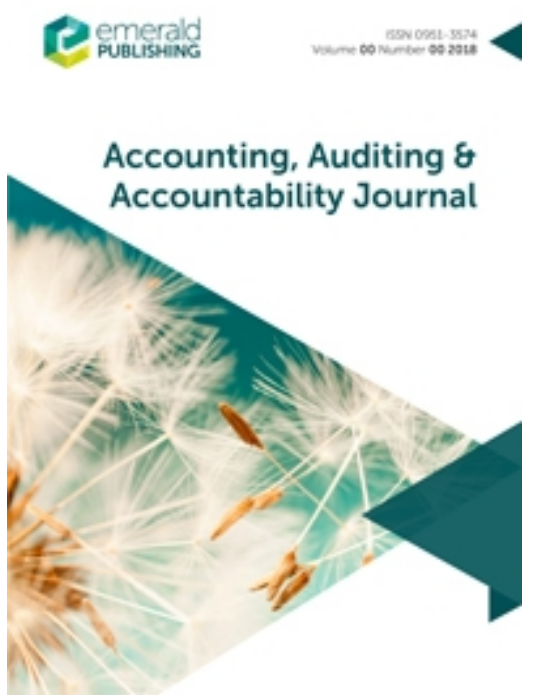

The spectacle of research assessment systems: insights from New Zealand and the United Kingdom

\begin{tabular}{|r|l|}
\hline Journal: & Accounting, Auditing \& Accountability Journal \\
\hline Manuscript ID & AAAJ-01-2019-3865.R2 \\
\hline Manuscript Type: & Research Paper \\
\hline Keywords: & performance measurement, research assessment, spectacle, universities \\
\hline
\end{tabular}




\title{
The spectacle of research assessment systems: insights from New Zealand and the United Kingdom
}

\author{
Structured abstract
}

\section{Purpose}

In this paper, we concentrate on the use of research assessment (RA) systems in universities in New Zealand (NZ) and the United Kingdom (UK). Primarily we focus on PBRF and REF, and explore differences between these systems on individual and systemic levels. We ask ourselves in what way(s) the systemic differences between PBRF and REF actually make a difference to how the two RA systems are experienced by academic staff.

\section{Design/methodology/approach}

This research is exploratory and draws on 19 interviews in which accounting researchers from both countries offer reflections on their careers and how RA (systems) have influenced these careers. The stories they tell are classified by regarding RA in universities as a manifestation of the spectacle society, following Debord (1992) and Flyverbom and Reinecke (2017).

\section{Findings}

Both UK and New Zealand academics concur that their research activities and views on research are very much shaped by journal rankings and citations these days. Among UK academics, there seems to be a greater critical attitude towards the benefits and drawbacks of REF, which might have to do with the history of REF in their country. Relatively speaking, in New Zealand, individualism seems to have grown after the introduction of the PBRF, with little active push back against the system. Cultural aspects may partially explain this outcome. Academics in both countries lament the lack of focus on practitioner issues that the increased significance of RA seems to have evoked.

\section{Research limitations/implications}

This research is context-specific and may have limited applicability to other situations, academics or countries.

\section{Practical implications}

RA and RA systems seem to be here to stay. However, as academics we can, and ought to, take responsibility to try to ensure that these systems reflect the future of accounting (research) we wish to create. It is certainly not mainly or solely up to upper management officials to set this in motion, as has occasionally been claimed in previous literature. Some of the academics who participated in this research actively sought to bring about a different future. 


\section{Originality/value}

This research provides a unique contextual analysis of accounting academics' perspectives and reactions to RA and RA systems and the impact these have had on their careers across two countries. In addition, the paper offers valuable critical reflections on the application of Debord's (1992) notion of the spectacle society in future accounting studies. We find more mixed and nuanced views on RA in academia than many previous studies have shown. 


\section{The spectacle of research assessment systems: insights from New Zealand and the United Kingdom}

And I remember a particular ex-colleague... I never knew what he did in terms of research, because he never talked about what he researched and what his ideas were. It was just 'I've got X number of three-star papers but according to this ranking, this one could possibly be a four on a good day'... And I kind of thought, 'well if you're in that place, isn't this no different to going back to selling extras on insurance policies?' (UK SL5)

\section{Introduction}

Performance-based research funding and assessment has been increasingly introduced in many developed nations as governments seek to encourage more, and (supposedly) more societally relevant, university research. Researchers have considered the increasing managerialism into academics' lives as a consequence of this development, sketching mainly the detrimental effects thereof (e.g., Agyemang and Broadbent, 2015; Knights and Clarke, 2014; Northcott and Linacre, 2010; Roa, Beggs, Williams, and Moller, 2009; Salter, Salandra, and Walker, 2017). Others have analysed the effects of research assessment (RA) systems on university life more generally. For example, Bogt and Scapens (2012) argue that RA systems, which are often output-based, relocate assessment subjectivities to higher management echelons, thus creating anxiety among university staff about how the systems will be used. Humphrey and Lukka (2011) lament the "battery-hen" style of research; shifting notions of quality; demotivation among university personnel; and anti-intellectual tendencies that can be witnessed since universities introduced RA systems. They call for pushback on these developments. Apart from increasing measurement, and the constraints and pressures this places on individuals and departments, there remains concern about the growing divide between academic research and the problems and issues to which practitioners seek answers (Tucker and Parker, 2014; Tilt, 2010; cf. Lowe and Tucker, 2014; Tucker and Schaltegger, 2016).

In this paper, we explore differences on individual and systemic levels of university RA systems. It seems to us that the effects of such RA exercises have too easily been homogenized in some of the previous literature (e.g., see Lorenz, 2012). Extant RA systems are obviously not all the same: the United Kingdom (UK) system differs, for example, from the Australian or New Zealand (NZ) systems; and the much more decentralized forms of assessment in the Netherlands or France are again totally different (Bogt and Scapens, 2012; Cooper and Otley, 1998). Similarly, the literature tends to polarize into writers who champion the positive aspects of RA systems (e.g., Lejeune, Davies and Starkey, 2015) and others who see no good in them at all (e.g., Lorenz, 2012; Willmott, 1995, 2011, 2013). Our assumption is that individual academics will probably hold different opinions about the RA systems they are confronted with as well. Thus, we take the perspective of assuming difference in this paper: difference between systems and difference in individuals' reactions to systems ${ }^{\mathrm{i}}$. To explore this assumption, we interviewed academics at different career points, who are subject to two different RA systems - UK and NZ.

Among others, qua systems, the UK assesses departments and not individuals, while NZ primarily assesses individuals. Consequently, our research question is: does this systemic difference actually make a difference to how the two RA systems are experienced by academic staff? Potentially, assessment is 'just' assessment and individual researchers' responses to RA remain the same irrespective of the system. This possibility would refute our assumption of difference. However, we anticipate that people's responses do differ, and that academics react 
to RA by either accepting the system, its goals and what it has to offer them; or by resenting it and perceiving it as an attack on their academic identity or status. For some, assessment may provide an opportunity to demonstrate that they can achieve something others find important; while for others it may represent a chafing imposition that seriously limits their academic freedom. Thus, returning to the theme of difference, we ask: to what extent, and how exactly, is there difference in the difference? Are there points of identity and commonalities in how academics react to RA systems whereby the same differences are reproduced over time, or not?

We posit that what individual staff members reproduce in their academic lives in the two countries occurs within the so-called 'spectacle' of performance measurement, as it is shaped by RA systems. This viewpoint informs our choice of theoretical framework in Section 3. The word 'spectacle' is etymologically derived from specere (Latin for 'to look') - i.e., it is grounded in the episteme of vision. A spectacle, therefore, concentrates on what is seen. RA systems exist to make 'research results' visible. What once was a very private form of creativity and action (academic writing, debate and discussion) may be said to have been recast as a very public spectacle through the introduction and proliferation of RA systems (Lorenz, 2012). Much of the impetus for this change has been attributed to the implementation of new public management (NPM) principles in academia. Lorenz criticizes this development, and the subsequent rise and importance of university management and performance measurement systems, claiming that:

... the solution proposed in NPM is always more management, more efficiency, and more control - typically starting from increasing self-control (for example, in the form of standardized self-evaluations). It is no coincidence therefore that the obsessive rhetoric about professionalization [of academic work] started at the same time as the NPM managers made their appearance in the universities ... (p. 616).

We believe that RA systems function as spectacles through which, among others, academic research becomes valued, stimulated and judged by academics, their managers, and other stakeholders who see value in using such systems (cf. Uddin, Gumb and Kasumba, 2011). The key source on spectacle-ization used in this paper is Guy Debord's (1992) theory of the spectacle society, which Flyverbom and Reinecke (2017) claim has much potential for organizational (and thus accounting) research.

We analyse the academic careers of accounting researchers in relation to the RA systems they have been and currently are confronted with. We find that the proliferation of RA systems has certainly impacted their career development, but not solely in the negative ways many previous studies have suggested. Some academics see great merit in being assessed through especially the NZ system. Hence, we find support for one of our notions of difference. Secondly, this study compares an individually-based RA system (NZ) with a group-based system (UK), questioning whether systemic differences actually have much traction for the individual researcher. We also see this. Particularly in NZ, researchers seem mostly unlikely to be concerned to change the 'rules' or underlying principles of the system they are subjected to. In contrast, we see in the UK a group-based system that somehow allows participants to perceive and act upon the inherent struggles associated with performance measurement. Several UK participants consequently argue that they could and should work for 'better rules' to ameliorate the substantial adverse effects of their RA system on university life. However, if we follow Debord (1992), the paradoxical result of introducing RA systems is the hyper-individualization of research. This is witnessed in both countries: the goal of RA systems Debord would predict (the individualization of outputs) has been reached, but it has reversed itself by rejecting the institution as a coherent and cohesive place to work. In other words, now that increased RA has achieved individualization, an associated and paradoxical result has emerged: an intense 
centrifugal force that may slowly tear research staff, and perhaps even universities in their entirety, apart. This reiterates but also intensifies some results from previous work on performance measurement in universities (Bogt and Scapens, 2012; Humphrey and Lukka, 2011).

In the next section, we outline the literature on the effects of RA systems that were designed to manage and measure research performance in universities, and present themes from this literature that have shaped academic staff's views on the role and content of (their) research following these RA systems' introduction. Thereafter, in Section 3, we explain the theoretical framework for this paper - the interpretation of RA systems as a spectacle. Our research method is outlined in Section 4, before the main findings are presented and discussed in Section 5. In our conclusions (Section 6), some surprises in the research results are acknowledged, as are areas for future research. Among others, this section discusses whether the repetitions and differences in RA systems we find are indeed easily interpretable forms of the spectacle society with predictable effects, as Debord (1992) would suggest.

\section{Measuring research performance}

\subsection{RA systems in two countries}

Verhaeghe (2014) believes that RA systems were first introduced in academia in the late-1980s/ early-1990s to spotlight and enable universities to dismiss academics who performed poorly but could not otherwise be laid off easily. He purports that over the course of the next 15 years, such systems began to dominate university life as governments demanded greater 'transparency' of universities. 'Transparency' meant the 'monetarization' of work life. Universities and their academics were submitted to cost-benefit analyses; for instance: what does an accounting and finance department cost, and what does it produce in additional (societal) welfare? 'Relevance', defined in economic terms, became all important in RA (Lorenz, 2012). Because the causal link between what is researched and taught, and a university's economic performance, cannot be accurately established, 'monetarization' commodified the number of papers published in the highest-rated journals (according to a particular predefined standard), the value of research grants obtained, and narratives of practical/societal impact. Thus, more or less, an 'imaginary' of dissemination and effects was developed across many nations in the aforementioned 15 years (Verhaeghe, 2014). Nonetheless, there was real significance of the measures that were gradually developed for individual academics and their institutions. Jobs, promotions and research budgets became linked to the results of 'monetarization'. Hence research is now a commodity. It can be seen as an artefact that is bought and sold on the academic 'marketplace' (Humphrey and Lukka, 2011). While research and writing were highly individual and personal endeavours in the 1960s, and the discussion of ideas was fairly powerful and deemed important by many university managers; nowadays internationally the number of publications in specific, predetermined journals seems to count the most if one is to be called a 'proper' academic. Conjointly with this change in academia, a greater sense of managerialism has been introduced in universities through the implementation of NPM principles, as stated in Section 1 (cf. Bovens, 2005; Humphrey and Lukka, 2011; Kallio et al., 2015, 2017; Lorenz, 2012). Two countries in which these developments can clearly be seen are the UK and NZ. Approximately every five years since 1986, the UK has assessed research quality; first through a 'Research Selectivity Exercise' (RSE) in 1992, 1996, 2001, 2008; through a 'Research Assessment Exercise' (RAE) in 2013; and, from 2014 onwards, through the 'Research Excellence Framework' (REF) (Bogt and Scapens, 2012; Cooper and Otley, 1998). The results of this $\mathrm{RSE} / \mathrm{RAE} / \mathrm{REF}$ exercise, which is conducted at the group/departmental level of every 
university, inform part of a university's government funding, in addition to grant funding from various Research Councils (Hare, 2003). The first RA exercise in UK universities, under the Thatcher government, was conducted in the hope of developing a transparent allocation method of funds to UK universities at a time of tight budgetary controls. Universities' research funding was based on the quality rating of 37 selected subject areas, which were each to be accompanied by five research outputs per university. Universities could provide up to four pages explaining their submission. Ratings were compiled within chambers by a committee of mainly senior academics, who were subdivided into teams across the subject areas (Jump, 2013). Jump asserts that this first exercise was biased towards larger departments and lacked consistency in criteria and approaches across subject areas. Assessment panels in later exercises therefore were required to be more open about their criteria for evaluation and methods of analysis.

REF's main aim is to discharge accountability for public investments in research, which ought to (eventually) achieve an efficient allocation of UK government resources. Hence, this aim concurs with that of the 1986 exercise that was heavily criticized for its indecipherable approach - but the impact on academic staff has become much more extensive (Willmott, 1995, 2011, 2013). There are currently approximately 140 universities involved in the REF assessment. The REF ranking of departments (rather than of subject areas, although the two are obviously not totally disjoint) is based on a four-star scale. Departments rated four-star are granted more research UK government funding, while lower ranked departments are allocated less. Bogt and Scapens (2012) note that the media ${ }^{\text {ii }}$ have utilized REF ratings (and those of the equivalent teaching quality exercise, called ' $\mathrm{TEF}$ ') to rank universities through league tables. Kellard and Sliwa (2016) suggest that academic institutions producing high quality research according to such tables are not always the traditional 'elite' institutions and that changes in league tables related to quality differences might lead to changes in societal beliefs as to a university's overall quality. This may result in universities seeking to reward and retain longserving academics with outstanding research track records (at least, according to REF) and thus increasing the vulnerability of early career academics. In REF 2014, universities could select research-active academics to form a group (called a 'Unit of Assessment' or UoA). The REF submission from the UoA comprised four publications for each individual. For the upcoming REF 2021, all research-active staff must be included in a UoA, but the average of $2 \frac{1}{2}$ outputs per staff member are 'decoupled' from individual staff (minima and maxima are subject to particular conditions). UoAs must also submit a limited number of case studies demonstrating practical 'impact' through academic research. In addition, an institutional and UoA statement on their research environment is required (Department for the Economy et al., 2019).

A so-called 'Performance-based Research Fund' (PBRF) was introduced in NZ in 2003. PBRF was explicitly informed by UK RSE developments, but the NZ government decided to deviate from RSE, as they felt that a departmental or disciplinary-based assessment regime would not work in the context of NZ's relatively small tertiary system, since not all disciplinary areas were represented across the entire country (given that there are only eight universities). Before 2003, government had funded NZ universities on a bulk basis using Effective Full Time Students (EFTS) as the main criterion. The then Ministry of Education believed that the universities' accountability was insufficient in specific areas, particularly when it came to research. A so-called 'Tertiary Advisory Commission' (TEAC) was subsequently installed, which, among others, proposed that future research funding should be separated from funding for teaching and learning. This effectively laid the foundation for PBRF.

Since 2003, four rounds of PBRF assessments have been completed (in 2003, 2006, 2012 and 2018). The results of the fourth PBRF assessment became available in early 2019. PBRF demands individual academics to submit a portfolio for assessment by a panel of peer- 
reviewers (Buckle and Creedy, 2018). Research quality, from the viewpoint of PBRF, is based on three components which, over time, have held varying weights. They are: 'research output', 'peer-esteem', and 'contribution to research environment'. In terms of their relative weights, research output has always been most valued. Evidence for the first component is typically based on publications or presentations that are classified into four 'nominated research outputs' and numerous 'other research outputs'. 'Peer-esteem' evidence concerns recognition in the form of prizes, awards, and invitations to speak at (international) conferences. Finally, 'contribution to research environment' includes aspects including $\mathrm{PhD}$ supervision and the receipt of research grants.

The reasons why we examine the UK and NZ in this paper are that, as noted in Section 1, the two systems are differently focused: they primarily consider individuals (NZ, PBRF) or groups of individuals (UK, REF). Thereby, they provide 'sameness' and 'difference'. While 'research quality' has been a growing rhetoric in the UK REF cycle, with the development of 'impact case studies' as a structured response to this demand (Tilley, Ball and Cassidy, 2018), it has been less emphasized in NZ, being generally captured under the 'contribution to the research environment' component (TEC 2004, 2006, 2012, 2018). Both systems deem obtaining sufficient research outputs (albeit at different levels and measured in different ways) to be very important. Our prior argument of 'monetarization' thus holds true in both countries, and effectively supports our notion of sameness. However, we are mainly interested in whether the differences between PBRF and REF also mean that accounting researchers from these two countries view their own research (career) differently. Different levels of seniority may also result in different views on this. We conjecture that especially accounting researchers, given the domain they work in, ought to be able to grasp and reflect on the functioning and underlying reasons for RA systems such as PBRF and REF (Humphrey and Lukka, 2011). In so doing, we treat PBRF and REF as exemplars of the spectacle society. This view will be explicated in Section 3 .

\subsection{Detrimental effects of research performance assessment}

Many papers have been published about the possibly harmful effects of RA systems in academia. This literature has often countered the assumption that universities ought to be run as regular businesses to foster (more) useful and valuable knowledge and research that appeals to the public eye (e.g., see Lorenz, 2012; Lowrie and Willmott, 2009; Tourish and Willmott, 2015; Willmott, 1995, 2011, 2013). Inter alia, literature has questioned why researchers must have a particular ranking for their publications over a certain period of time; and why it is not commonly seen as a problem that many of these rankings involve academic publishers with particular vested interests to defend. In addition, the general tendency among academics to submit papers to 'high-ranking' journals first (as journal prestige has increasingly started to dominate the submission process) has been criticized in the literature (Humphrey and Lukka, 2011). Furthermore, it has been suggested that reviewers may have become less accepting of different or unusual viewpoints, as they (un)wittingly prefer defending their own position and lines of thinking over accepting quirky, deviant or new ideas. All this could stifle creativity and new developments in research, including in accounting (Bogt and Scapens, 2012). Cederstrom and Hoedemaekers (2012) assert that no matter these negative consequences, academics are likely to play a publication 'game', often eschewing the issues that are deemed important by practitioners, as their current research time needs to be defended, and if possible, extended (cf. Lowe and Tucker, 2014; Tucker and Parker, 2014). It is typically acknowledged that this is the only way to move ahead in academia these days. Some authors have warned that this may lead 
to increasing individualism and a decline of collegiality across, and certainly within, university departments and disciplines (Bogt and Scapens, 2012; Humphrey and Lukka, 2011).

Agyemang and Broadbent (2015) examined the management control systems developed by UK universities across their business and management disciplines following the introduction of REF. A measure commonly used in UK-based universities to assess the quality of research contributions is the peer review of research outputs, via the Academy of Business Schools' (ABS) list of academic journals (which ranks journals from not-rated, through 1 to 4 stars, and $\left.4^{*}\right)$. iii The alleged simplicity and perceived legitimacy of the ABS list has facilitated its incorporation in the hiring and promotion of university staff. Agyemang and Broadbent (2015) assert that it has also signalled the advent of a culture of subordination and tight control in universities (cf. Lorenz, 2012).

An issue raised by Goldfinch (2003), specifically for NZ, is that PBRF disadvantages those staff members who concentrate on researching domestic issues. International research has become prioritized and domestic research from small countries (with unique cultural aspects) is relegated, as larger countries' domestic matters are deemed 'international'. Consequently, Roa et al. (2009) state that PBRF undermined Māoriiv-based research and encouraged researchers to focus on international research that might have more immediate appeal.

Based on a survey on RA impact, Curtis and Matthewman (2005) conclude that academics frequently felt they were overworked and stressed following PBRF implementation. They found a significant relationship between the extent of an individual's pessimism and poor PBRF results, and optimism and good PBRF results. In analysing the impact of PBRF on universities in greater detail, Curtis (2007) found that, in 2006, NZ universities tended to game the PBRF system by removing research inactive staff from participating, including re-writing their employment contracts so that they were essentially 'unemployed' over the census period. As with REF, one of the most significant effects of PBRF seems to have been greater surveillance of academic staff by senior management (cf. Lorenz, 2012). PBRF has also actively endorsed self-promotion, which may be contrary to the values of academics of particular cultural backgrounds, such as younger academics, women, Māori and Pasifika (Roa et al., 2009).

Northcott and Linacre (2010) fail to observe any improvement in the overall quality of the accounting publications following RA systems' introduction. Rather, they see a reduction in diversity, originality and practical relevance of accounting research. The researchers they surveyed believed that journal rankings had become a generally accepted indicator of journal quality. Good or high-ranking journals were frequently equated with good quality papers (cf. Macdonald and Kam, 2007).

\subsection{Further consequences of research performance assessment}

In contrast, Lejeune et al. (2015) surveyed the deans, directors of research, and research managers of UK business schools. A majority of their respondents reported that the impact 'agenda' stipulated by REF had changed the strategy and research outlook of many business schools, leading to a greater recognition of the diversity of contributions, considerations of a wider range of stakeholders in university management processes, and considerably influencing the design of future research. This contradicts the mainly negative views of academic staff exemplified in the previous section. Lorenz (2012, p. 616) is unsurprised by outcomes such as these, as "... power over the universities [has been] given to a group that was unprofessional in the original meaning of the word [i.e., university managers]". The only way to maintain the 
latter's power is to exploit and endorse the performance measurement systems that have been developed and help them to underline their professionalism.

Interestingly, Lejeune et al. (2015) claim that the focus on research quality within universities has oftentimes led to greater collaboration and communication within and between university departments, and more widely across universities. While they assert that the REF increased collegiality, this is firmly contradicted by other studies (e.g., see Bogt and Scapens, 2012; Humphrey and Lukka, 2011). Nevertheless, Lejeune et al. (2015) found that REF heightened risks in research commercialization, potential reductions in fundamental research, and reduced appreciation of teaching. Concerns also existed about the future of doctoral training, and the possible devaluation of DBA programs, which are typically not supported by UK funding bodies.

Summarizing the discussion in this section, we observe several themes emerging from the literature when considering specifically the effects of RA systems such as PBRF and REF on academic research. The views on the effects of these systems may differ between academics, managers and deans, as has been illustrated above. These themes are:

- Promotion of research with what is taken to be impact (Agyemang and Broadbent, 2015; Lejeune et al., 2015; Murphy and Sage, 2014);

- Stifling of creativity and innovation (Bogt and Scapens, 2012; Lorenz, 2012);

- Emphasis on research outputs (playing the publication 'game') (Cederstrom and Hoedemaekers, 2012);

- A greater sense of individualism vis-à-vis collectivism within and across universities (Humphrey and Lukka, 2011; Roa et al., 2009);

- Less attention to practitioner concerns and minority standpoints (Cederstrom and Hoedemaekers, 2012; Lejeune et al., 2015; Lorenz, 2012; Northcott and Linacre, 2010; Tucker and Parker, 2014);

- Defending the allocation of research time (Lejeune et al., 2015);

- The nature/future of PhD and DBA programs (Lejeune et al., 2015).

We will use these themes to guide our interpretations from our empirical research, as we explain in Section 4 and 5. We discuss and frame the perceived realities/experiences that the application of RA systems has brought to the research (career) of accounting academics, and how they have consequently changed their behaviors. The next section discusses the theoretical framework adopted in this paper.

\section{The spectacle of performance measurement}

Guy Debord is considered to be the theoretician of the spectacle society (1992; cf. Kaufmann, 2006, 2010). While very influential, especially in his native France, he was never employed at a university. In fact, he asserted that such employment would be counter-productive for an autonomous researcher. Research, for Debord, had to comprise the unencumbered investigation into existence, circumstance and the quality of human life. When research puts economic or institutional success above valuing human existence, it becomes propaganda in betrayal of life itself. This manifests itself in a show of dominance and privilege, wherein the autonomy and integrity of a researcher is sacrificed to the highest or most powerful bidder in society. The research that researchers produce then becomes 'spectacle': a performance of flashy appearance and ascendant power, which basically confirms or performs the economic privileges that rule society. Debord (1992) claims that only truly independent investigation 
undertaken in total self-determination is authentic enough to be truthful and fruitful. Thus, Debord dichotomizes radical independence of thought and awareness; and the 'spectacle' or endless repetition of clichés, images of trickery and self-interested distortion of thought and human existence.

Flyverbom and Reinecke (2017) argue that spectacles, in Debord's (1992) sense, may be at the heart of contemporary organizations and processes of organizing. They state that:

Creating dramatized representations of a reality, creating spectacles, is ... what most organizations do and what most organising is about: Creating a brand. Marketing a product. Doing leadership. Creating forecasts and visions in strategy. Narrating a corporate sustainability report. Even publishing a financial account. Submitting a tax return. One could argue that corporations themselves are modern incarnations of the Spectacle: A form that is narrated into being through PR and branding, and biography which is curated by the emerging profession of the corporate storyteller (p. 1626).

We claim that RA systems can be interpreted as exemplars of spectacles, and that performance measurement, as a practice, creates, changes and/or reinforces such spectacles, for example in universities (cf. Chwastiak, 2006; Vollmer, 2007). Since they aim to represent organizational life (and produce 'images' or an 'imaginary'), RA systems offer only a limited view of the 'goings on' in an organization (Covaleski and Dirsmith, 1990; Lowe and Puxty, 1989). However, through them, some 'goings on' come to be highlighted, whilst through their exclusion, other 'goings on' are deemed to be of lesser value and come to be suppressed. New 'goings on' may also be introduced in organizations because of performance measurement systems which are aided by accounting information, because "... what gets accounted for shapes organizational members' view of reality ... Accounting provides a self-evident and apparently objective way of thinking, talking and doing, cloaked behind a veil of blandness" (Covaleski and Dirsmith, 1990, p. 545). Thereby, accounting often provides the dominant imaginary or organizational spectacle that managers, as well as other organizational members, embrace and endorse. Consequently, Potter (2005) asserts that the application of accounting principles may introduce a level of certainty in organizations that does not actually exist. Accounting information, through its use of calculations and valuations, helps to sustain, introduce, change and/or rationalize certain practices and perspectives (i.e., particular manifestations of a spectacle) in organizations (Jack, 2017). In order for accounting to realize such rationalizations, organizational members must accept the reality that is being proposed thereby. In response to this reality, they may have to change their view of their organization and of the world in which it operates (i.e., of society) (Busco and Quattrone, 2018; Chwastiak, 2001, 2006; Ezzamel, 2012; Vollmer, 2007; Vosselman, 2014). If the spectacle is rejected, the audience or onlooker is at a loss. To what extent and in which way(s) such rejections of the spectacle occur in practice is unknown, even though theoretically it may be deemed important for organizational and societal change (Debord, 1992; cf. Humphrey and Lukka, 2011).

Flyverbom and Reinecke (2017) invite scholars to examine the 'making of' organizations through processes of representation and transformation. Since their theoretical source, Guy Debord (1992), believes that 'organizational truth' is a non sequitur and that 'truth' depends on the individual autonomy of vision, thought and investigation, the very idea of the 'making of' individuals/scholars (for instance, through RA) is an anathema to him. As stated, such a 'making of' would entail discursive practices, visual imagery and (theatrical) performance. This, Debord argues, essentially boils down to a spectacle of inauthenticity, conformity and the marketing of special interests. It may be claimed that universities' use of RA systems is a powerful assemblage of the aforementioned practices, images and performances, designed to 
represent university life in particular ways. Thereby, RA safeguards organizational hegemony, e.g. between and within universities, and between universities and government agencies. Debord alleges that societies, and the individuals comprising these societies, can relate to this spectacle only in ways which are not of their own choosing: their possible positions are limited. A spectacle is shared, collective, and a product of the hegemonic habitat; it is never grounded in autonomous observation or thought. Flyverbom and Reinecke (2017) do not necessarily hold the same view as Debord, as the discussion below will show.

Debord (1992) asks researchers, as well as other individuals, to thoroughly reflect on the relationship between 'reality' and its representation(s). According to Debord, spectacles conceal the dominant role of capital in society through commodification. Therefore, spectacles are mainly an oppressive control mechanism, stimulating pseudo-needs, societal reforms and fabricated desires under the guise of the development and evolution of society. Consequently, he believes that:

\section{The spectacle cannot be understood either as a deliberate distortion of the visual world or as a product of the technology of the mass dissemination of images. It is far better viewed as a weltanschaung that has been actualized, translated into the material realm - a world view transformed into an objective force" (Debord, 1992, p. 5).}

Hence, spectacles have a performative and transformative function (cf. Vosselman, 2014). They not only represent and describe society, but also shape society.

The notion of the spectacle has frequently been discussed in the sociological literature (e.g., see Baudrillard, 1981, 1999; Foucault, 1998; Lacan, 1977; Letiche, 2004; Levinas, 1969). The study of Uddin et al. (2011) is rare in explicitly examining the transformational nature of spectacles in an accounting setting. They analyse (changes in) the structure and content of participatory budgeting practices in the Kampala district of Uganda. The authors conclude that donor agencies' use of spectacle helped to install and control particular budgeting practices, despite original substantial resistance at the local level against some of the changes proposed. Uddin et al. (2011) plead for a greater use of Debord's (1992) analytical framework in future studies.

In this paper, we apply Flyverbom and Reinecke's (2017) three understandings of the relation between individuals and spectacles, when we interpret the experiences of accounting researchers with RA systems in the UK and NZ. Flyverbom and Reinecke (2017) see a spectacle as a form of: (1) fetishism, in which people accept a spectacle as it is, whilst recognising it is partial and limited; (2) as an entry point into a world which can be described as a 'hyper-reality', where people are not bothered by or interested in the limited nature of the spectacle; or (3) as a mechanism whose performative and transformative powers people recognise, partially (opportunistically) embrace and partially object to (potentially resulting in active resistance). In the present paper, we view REF and PBRF (and RA systems more generally) as exemplars of spectacles. We analyse how accounting academics in universities in the UK and NZ have approached their research (career) as a result of the introduction and proliferation of these systems. Adopting Flyverbom and Reinecke's framework allows us to understand a variety of responses that academics may have to RA initiatives. These responses need not always be negative, frustrated, angry or fierce, as many previous studies have suggested. We consequently do not claim from the outset that there are only or mainly detrimental effects of increased research performance measurement in academia. Following studies conducted in other settings (e.g., van der Kolk, Bogt and van Veen-Dirks, 2015), we could, for instance, well imagine that people may excel or become motivated by increased measurement and control practices in their work environment. The spectacle can also be 
reassuring, and individuals may see benefits from participating, thereby escaping from Debord's (1992) overwrought sense of independence and responsibility in academia. This may feel liberating and show in people's responses.

The first perspective that Flyverbom and Reinecke (2017) discern involves treating RA and RA systems as an invitation for fetishism. They ask what would happen if someone actively and willingly submits to the 'regime of truth' promoted by the RA system, even though it has been imposed upon them (cf. Miller and O'Leary, 1987). Representations, and their associated images, could then become so vital to people's lives and identities that they deliberately choose to remain locked-in. In such cases, the spectacle is commonly viewed as 'the way to go' (Debord, 1992). The pseudo-needs stipulated by, in our case, a RA system are supported, even if they are counterproductive for genuine researching and what a researcher would personally like to do (Flyverbom and Reinecke, 2017). There are several reasons why people might embrace such a stance. For instance, this behavior may be part of an individual's personal make-up. It may also be that someone can easily meet and/or relate to the targets or indicators promoted via the measurement system. Hence, the system may not be questioned because it safeguards one's interests. A system could also act as a driver for organizational members who are chiefly extrinsically motivated. They may need targets and indicators to function well (van der Kolk et al., 2015). However, this may also diminish their own, and/or other people's, intrinsic motivation (Frey and Oberholzer-Gee, 1997). As a consequence, universities may lose individuals who are mainly motivated intrinsically (Humphrey and Lukka, 2011).

The second perspective singled out by Flyverbom and Reinecke (2017) regards a spectacle as a simulacrum. This perspective is not explicitly covered by Debord (1992) but stems from the writings of Jean Baudrillard (cf. Boiral, 2013; Letiche, 2004; Macintosh, Shearer, Thorton and Welker, 2000; Uddin et al., 2011). Baudrillard (1981) describes simulacra as images without substance or quality. An example would be a picture of the American actor Marlon Brando, which someone perceives to be a representation of Italy (or the mafia), without further questioning. Simulacra present a tempting, repeated outlook on who someone or something might be or become. Baudrillard (1981) purports that by embracing and believing what a simulacrum portrays, without deeper analysis, one becomes increasingly detached from reality. Ultimately, people can describe their life events only in terms of the simulacrum. Their whole life is dominated by the signs or cues received through the simulacrum. They become the proverbial '(wo)man in the mirror' (pictured by a RA system for example), and live in what Baudrillard (2001) calls the 'Nothing'. There is nothing beyond representation in Baudrillard's view, and its manifestations are accepted at face value (Letiche, 2004).

The third perspective that Flyverbom and Reinecke (2017) set out covers the middle ground between fetishism and simulacra. This perspective deviates from the previous two in the sense that it is more dynamic and less oppressive. It presumes that even though a spectacle actively shapes reality, identities, relations and (organizational) practices through its performative and transformative function in ways that cannot always be predicted, people are able to partially see through them and reflect more thoroughly on what they experience. This diverges from Debord (1992), who does not consider such behavior to be possible. However, according to Flyverbom and Reinecke (2017), one may decide to relate to particular elements of a spectacle in specific ways, which can change over time. Pushback to RA efforts is consequently possible, although it may be temporary and limited (Uddin et al., 2011). Spectacles cannot totally hide the real state of affairs in this understanding of the spectacle (as in the simulacrum), or entice people to completely submit (as with fetishism). What comes to matter is what is performed, and how this performance is reflected upon by the individuals who claim to understand what is going on. Such reflective processes are always in flux with meanings and associations with 
(particular elements of) the spectacle changing over time. When research activities at universities are measured, what constitutes 'research', a (good) 'university' and 'measurement', can, for instance, be redefined in ways that cannot always be foreseen or controlled. The same holds for what constitutes a 'decent' or 'not-that-decent' researcher. Individuals may be looked upon in different ways as measurement increases, and may feel forced or urged to change their behaviour or stance on certain issues, which may again change the way they are viewed by, for instance, their departmental managers. As a consequence of this, researchers could try to change the measurement and assessment practices they are shaped by (e.g., by protesting against the consequences of REF or PBRF).

\section{Method}

In this paper, we concentrate on the effects of RA exercises introduced through PBRF and REF, given the themes set out at the end of Section 2.3. Our research entails the semi-structured interviewing of nineteen academics in $\mathrm{NZ}$ and the $\mathrm{UK}$ at a variety of levels in the academic hierarchy. Obviously, our sample does not allow us to claim that it is 'representative' of academia or of all accounting departments or accounting academics in these two countries. This is exploratory research wherein sensitising concepts such as 'fetish', 'spectacle' and 'hyper-reality' arise from subjects' stories of their careers. In terms of research content or the researcher's focus, fetishism glorifies economic 'success' and is enamoured by entrepreneurship and the achievements of the hyper-rich. Much business studies research meets these criteria (Green, 2019). A focus on spectacle examines the facade of (strategies of) success. It sees leadership as theatrical, wherein appearances play a crucial role. One sells oneself, one's product and one's vision. Finally, in the hyper-real perspective, success is related to a regime of performativity wherein one can never be sure if things are what they seem to be or will remain the same. An organization (such as a university) is lost in appearances, whereby 'real' value is indeterminant and (research) contributions are inherently unstable. The three perspectives are rarely completely independent, and can therefore be found in different mixes and forms (Flyverbom and Reinecke, 2017). Thus, we would expect to find them, in various combinations, in our interview accounts. The three positions are descriptors of ways of seeing both the objects of research (as discussed in Section 6) and the role or identity of researchers (as discussed in Section 5).

Our interviewees talked about their doing of research and how they conceptualized their context (i.e., their work environment), wherein RA had become a self-evident dimension to the way they behaved. We assumed that our interviewees were attuned to their identity as researchers and were able to reflect thereon (Alvesson, 2011; Humphrey and Lukka, 2011). They were at various stages of their academic careers, but they all had active research portfolios and could hence talk, to some extent, from a position of sameness. While Alvesson (2011) recommends supplementary interviews and participant observation as ways of increasing the persuasiveness of interviews as research material, we managed this in some cases by drawing on our personal knowledge of the interviewees; and in all other cases on the history of the institutions and accounting departments at which they had been or currently were employed.

Our core empirical data is necessarily self-reflective. We put forward the view that self-identity is not strictly chronological but experienced subjectively by interviewees as "... spontaneous acts of meaning-making that take place and interweave through many moments of discursive time and space" (Cunliffe, Luhman and Boje, 2004, p. 262). Thus we assumed that when interviewees narrated their past and present attitudes towards research, and their opportunities and frustrations, they created "performances in the moment" (ibid., p. 272) (cf. Denzin, 2014). 
Our research probes whether, where and how these performances displayed 'fetish', 'spectacle' and/or 'hyper-real' foci, and in what way(s) these performances exhibited difference(s).

We developed a list of nine probing questions to use in case we felt participants drifted from the main themes of each interview: one's career as a researcher, the effects of RA systems thereon, and the research they had consequently undertaken. Among others, these questions focused on the impact of researchers' self-perceived stature in academia on the research they undertook; general considerations about research quality; and the role of publications in academic and professional journals therein and thereon. Every interview started from the same opening question: "What has your research career in academia been like thus far?". The interviewees did not know in advance which questions they would be asked. They only knew that the interview would focus on their research career. This alone determined whether they participated or decided to decline. Interviews were undertaken with ten accounting academics in the UK (from eight universities) and nine academics in NZ (from six universities). They were all conducted in mid to late 2018. The interviewees lasted between 45 minutes and two hours. Approximately half of the participating academics stemmed from the personal networks of the authors; the other half were new contacts. The participants were solely selected based on their current academic position. At no stage was it considered (not) to select someone based on their personal stance on the influence of RA on academic life. Indeed, these views were largely unknown to the authors, even in the case of the academics they had been in touch with before. The research-active academics who ultimately provided information were four Lecturers (L) (two in each country), eight Senior Lecturers (SL) and one Associate Professor (four in NZ and five in the UK), and six Professors (P) (three in each country). They had been academics (but not necessarily only in accounting departments) between two to almost 40 years and had conducted accounting research throughout their careers. In terms of research outputs, their Hindices were between 1 and 20 at the time of their interview. An overview of the participants can be found in Table 1 .

\section{[ INSERT TABLE 1 HERE]}

Intensive work in analysis was required to develop insights from the data we gathered (Alvesson, 2011). We read and re-read our mostly unstructured interview accounts, before we analysed them using the themes which the literature suggested might feature in discussions on how academics make sense of their research lives (see Section 2.3 for details). We present the interpretations we finally agreed upon. We could find traces of many of these themes in the interviews, but we also found an additional theme, which is presented in Section 5.4. Excerpts from the interviews alluding to the three understandings of the 'spectacle' set forth by Flyverbom and Reinecke (2017) are provided and discussed in Sections 5.1, 5.2 and 5.3. We use these analyses in Section 5.4 to compare and contrast the previously mentioned summary themes for each nation and their respective RA systems, so as to answer our main research question: in what way, and to what extent, are there differences within the difference?

When quotes are used, they are referred to by country, university number and position number, in order to ensure anonymity. So, for instance, the acronym UK SL5 denotes the fifth Senior Lecturer/Associate Professor interviewed in the UK. The next section presents our research findings. 


\section{Findings}

All academics, both in the UK and NZ, addressed the performative and transformative function of REF and PBRF. Research and research output, framed in specific ways through REF and PBRF, had clearly become more important in their universities, particularly in the last two decades. Many academics indicated that it was via REF or PBRF that they had for the first time been confronted with extensive RA frameworks, which were intended to have concrete consequences in practice - their own practice. For example, when recounting the history of accounting departments in NZ, NZ SL2 stated:

You had to do research but there was no pressure to continuously do that. You could take a research project, go and do your research, and present your findings to the practitioners. There was no pressure to go and publish in A-rated journals, B-rated journals. That pressure wasn't there ... before the PBRF arrived [in 2003].

Similar views were expressed in the UK, as can be seen by the below quote from UK SL4. This participant was head of a research group, and noted that, contrary to 10-15 years ago, university management now:

... cares where you publish. It's all about the REF. It's aggressively measured and people are required to meet targets. Some people in our department who have not published in many years have now been transferred to teaching contracts, because people have to be counted for REF purposes. This is probably part of the university's strategy.

By transferring staff to teaching contracts, and away from research and teaching contracts, universities did not have to 'count' these academics for the REF submission, which could impact positively on the funding subsequently received from the UK government. This is an example of the transformative nature of spectacles, which we would term detrimental (cf. Curtis, 2007). Another example concerns the pressure felt by NZ SL2 to publish in A- and Brated journals. All of these effects have been discussed in previous literature (e.g., Lorenz, 2012; Bogt and Scapens, 2012). However, we also found some novel insights, which are presented across the following sub-sections.

As they talked about their experiences in academia, participants mainly addressed their current research issues. Therefore, these issues are emphasized next. The fact that REF and RPBF often were the first RA systems they had to deal with that clearly affected their research and position within their department, may explain this focus in the interviews.

\subsection{Research assessment experienced as a form of fetishism}

The first perspective of the spectacle singled out for analysis involves treating RA as an invitation for fetishism (Flyverbom and Reinecke, 2017), in which people actually enjoy being periodically assessed and their performance being measured. This may especially act as a driver for those academics who are extrinsically motivated (cf. van der Kolk et al. 2015). Interestingly, and contrary to much that has been said in the extant literature, several academics saw real benefits in REF and PBRF, and found it to be of no or only a limited problem submitting to these systems.

For instance, the practice of counting publications for promotion may be viewed as one of the major consequences of the introduction of RA systems in academia (Cederstrom and Hoedemaekers, 2012; Humphrey and Lukka, 2011). In some publications (e.g., Bogt and 
Scapens, 2012) this has been associated with the stifling of creativity and an emphasis on quickly pushing for new publications that very much align with one's previous publications. Even though such practices were recognized by, for instance, NZ P1, this interviewee, along with a number of other interviewees from NZ, mainly stressed the benefits of PBRF that they had personally experienced, instead of addressing the aforementioned problems:

Not everybody liked the PBRF and not everybody thought it was a good idea, but I thought that it was actually very healthy for us ... Having a regular process where you have to sit down and put together your [research] portfolio and say 'this is what I've done', knowing it's going to be compared with other people generates focus ... A lot of people only see the costs, but I think there are benefits to the individual that a lot of people don't see.

NZ P3 noted other positive effects of PBRF, and explained why they believed a focus on research performance, and impact factors in particular, worked well for them:

I develop my impact factors very assiduously, I use Publons ... I [also] want my download rate on SSRN to push up [and] that will impact on my other download rates and the G-indices and the H-indices which I use when I want to compare myself with other people for promotion ... If people don't read you and cite you there's no point. You're just in a dead-end tunnel somewhere.

The above statement suggest that NZ P3 was clearly motivated by PBRF guidelines when preparing and submitting their publications. NZ SL3 addressed the influence of journal rankings in PBRF on their own research as well, stating:

I'm busy with social capital at the moment, which isn't really my interest field. But because I know there's a strong possibility of getting it into AOS, I do it ... I have to try and get into the A or $A^{*}$ journals.

These views illustrate that researchers may be tempted to change their research outlook and thematic focus when they know they will be assessed individually, even though they might be intrinsically motivated to pursue other topics. However, this is not necessarily regarded as a problem since obtaining higher $\mathrm{H}$-indices or getting into $\mathrm{A}$ (or $\mathrm{A}^{*}$ ) journals extrinsically motivates them. In line with the findings of the van der Kolk et al. (2015) study in Dutch municipalities, it may be that elaborate RA systems such as PBRF may attract or have attracted individuals who like or need to be extrinsically motivated. They then wittingly submit to these systems.

Some slight disagreement with PBRF was found in the accounts of some NZ participants, even when they experienced RA as a fetish. NZ P2, for instance, while agreeing in principle with PBRF, was not compelled by the intricacies of its measurement. Nevertheless, they also subscribed to it, noting:

Originally, I did research because I quite liked it ... [Also] because I thought it was the right thing to do ... Now it's been a requirement, I feel the push to do it. Being pushed, forced actually, I resent that.

In addition to being negative about the increased focus on research performance, NZ P2 also recognized that the system encouraged attention to self-interest.

In the UK, where all universities are assessed through a group or departmental level measurement system (REF), interviewees explicitly addressed the publication 'game' that REF had stimulated. For example, UK P1 noted: 
One senior mentor told me that there's a game taking place here [through the REF], but provided you are ahead of the game rather than behind and being forced to play into it, it's better to be ahead of it ... It's going to stay and you have got to address it.

This participant, in choosing their research topics in the face of potential managerial conflict, conceded that: "So in terms of [academic work], I want people to look at my H-index. [My topic] might not interest you. Fair enough. But [given my H-index value] don't question the relevance of it." This rationale encouraged them to choose particular research topics to stay ahead of the 'game' and avoid comments from departmental managers. UK P1 was therefore generally positive about REF's prioritization of research performance and its focus on particular publications and claimed that they had already unwittingly emphasized (what later came to be) REF requirements in their work since the late 1990s. Hence, they found themselves a serious academic. However, they also indicated that: “... what is perhaps a little bit concerning is that funders and institutions are asking scholars to articulate their impact even long before doing the work. You don't do research to create a particular impact. You do the research and then it makes sense to track it if it is having any impact." This harks back to comments made in earlier studies about an overzealous emphasis on impactful research that can be witnessed across the business and management disciplines, and the potential detrimental effects hereof (Agyemang and Broadbent, 2015; Murphy and Sage, 2014). UK P1 believed this trend was affecting accounting research as well.

UK SL1 also accepted that there was a game going on when it came to publishing accounting research, but they had few difficulties herewith:

[T] his is the game... you need to get things published [and] in the right outlets... it's the game that needs to be played for me to do the job that I want to do ... [I]f you had lots of publications for practitioners with lots of impact, but you didn't also have a reasonable number of publications at three star or higher, I think it would dent your credibility dramatically.

This recognition that the REF prioritized particular views on RA was similarly described by UK SL3, who argued that:

[I] you have an idea, you think whether you can apply for money or research grants... because it is a requirement these days to get some money... [Then prepare to write] publications in academic journals [even though] sometimes that's not the right way of doing, but that's what counts. You have to think about whether that journal is good enough for your $C V$ and for the people who are doing your assessment.

These views are very much in line with Cederstrom and Hoedemaekers' (2012) conclusions about the greater emphasis that has been placed on publishing papers in specific academic journals since the advent of RA systems (cf. Lorenz, 2012). Even though playing the publication 'game' seemed to be on accounting academics' minds in the UK, this was not necessarily perceived as a bad thing, apart from the fact that researchers might think too hard about the potential impact of their research before actually conducting the research, as indicated by UK P1 and UK SL3. This particular problem seems to have been exacerbated by funding bodies asking for impactful research when applications are submitted.

UK SL4 was also relatively positive about the increased emphasis on research publications in their institute, although they found it important that assessments through REF occurred at the departmental level, and not at the individual level: 
I don't mind my department or my school being categorized. It's not so personal. I would mind very much if it was that personal. [It would take] me straight back to A levels. 'Are you good enough, what are you, are you an AB or an A star?'. Oh, that sounds horrid.

This particular participant suggested that group assessments, through a system such as REF, could help to sustain niche research, which might otherwise be in jeopardy of losing its appeal:

You could be somebody who has written a lot and done a lot of research in accounting history, for example. You have spent hours in the archives and done a really solid piece of work. You've analysed it, written it up, and published it in specialist accounting history journals ... [Y]ou know that's good solid research in that niche field. Unfortunately, in that niche field there are no three-star and four-star publications to be had ... [Y] ou can have an impact obviously from very good research which can be solid, but you can have other pieces of research which don't necessarily have an impact - but that doesn't mean that it's not good research.

Given the rise of performance measurement in academia, which UK SL4 believed could not be avoided or stopped (as did UK P1), and the support of and personal interest in niche research by these researchers, they were very much in favour of group assessment. Although there was increasing pressure to publish in their department, UK SL4 asserted they could handle this pressure. This particular participant did not feel that increased performance measurement would inevitably lead to the suppression of certain types or styles of research, which is contrary to what Bogt and Scapens (2012), Chua (2019) and Lorenz (2012) have suggested.

The aforementioned quotes all relate to academics who had no major or only limited issues with (particular aspects of) REF or PBRF in (the shaping of) their own research (career). Especially some of the NZ academics at a higher level of appointment seemed to be very satisfied with PBRF. What, however, if somebody is so encapsulated by PBRF or REF requirements that these completely determine their views and desires as a researcher? This is discussed next.

\subsection{Research assessment experienced as a simulacrum}

We have noted that spectacles can invoke simulacra that sketch tempting outlooks on who someone might become, if they 'do what matters' (Baudrillard, 2001; Flyverbom and Reinecke, 2017). This then starts to dominate one's life, with progressively less emphasis on reflection. The search for promotion and 'moving up the university ranks' may be interpreted as such a simulacrum, as was evident in UK L1's case. This was the only interviewee we spoke with who freely admitted that promotion mattered an awful lot to them, given their competitive attitude, and that it completely dominated their career at this stage.

UK L1 was totally committed to meeting the publication requirements (of a paper in a 4 or $4 *$ rated journal according to the ABS list) to become Senior Lecturer in their institute. However, as a consequence of not yet having such a 'top-level' publication under their belt, it was felt that: "I'm still not a part of the researching side of my department." UK L1 had therefore recently decided to co-author papers. The determination to do this had settled in after a conversation with their head of department: "I said to him 'I still want to produce some papers of my own that are mine'. And his expression was 'you could choose to try and do [that], go through the pain of producing those papers because you want to get the monkey off your back, and you know you can do it. But instead of trying to get the monkey off your back, the other 
option is to just shoot the monkey'." This is exactly what UK L1 proceeded to do. They have come to believe that 'top-rated' publications could generate:

... a great feeling, to know that you really do know more about something that you're passionate about than anybody else and you can then use that knowledge for good and can share it ...But what am I good at now? I'm great at all the stuff except for the bit that in some circles really matters, which is producing those papers. ... [But] I'm competitive, I want to be better. I want to be better than [my co-authors] at the things they're good at.

UK L1 had a long career in management before moving to academia, and they had among others been a successful business owner. They also played sports regularly. Their dedication to become a 'top-level' academic in their department, defined entirely by REF, may perhaps be explained by this background. Following Baudrillard (2001), UK L1 could be assumed to operate in the hyper-real, only being able to reflect on their academic career on the basis of REF. We purport that this particular view has not been emphasized very much in the literature on performance measurement and management in universities. UK L1 did not see any negative effects from increased RA in universities, nor were they able to sketch an extended viewpoint on academic life beyond REF requirements.

The quote at the beginning of this paper provides another, similar example of a simulacrum specifically in relation to UK SL5's ex-colleague who never discussed their research topics, but rather the ranking of the journals in which their work had been published. Anecdotal evidence from conferences that the authors of this paper recently attended seems to suggest the same: there were quite a few researchers who talked and related to one another based on their publication record only, and did not seem to mind that they did this. However, contrary to Baudrillard (2001), most of the academics we spoke with for this project acknowledged that they (sometimes) managed to see beyond these representations, admitting that there were relevant aspects to academic research beyond what PBRF and REF stipulated that they found important, and that they somehow tried to fit into their career as well. We thus move to a view of the spectacle as a transformative mechanism.

\subsection{Research assessment experienced as a transformative mechanism}

As indicated at the start of Section 5, the majority of our participants addressed, in various ways, the performative effects of the introduction of REF and PBRF at the university level. However, in this particular understanding of the spectacle, academics are not only confronted with such effects, possibly unexpectedly so, but they relate to them in particular ways and partially choose their own position in their relation to them. One therefore does not always only submit oneself to REF or PBRF, or become seduced thereby. Oppression may be accompanied by subtle (or not that subtle) resistance and attempts to turn things around.

Such resistance was found in particular in the accounts of several UK participants. For example, UK P2 offered a lengthy, critical reflection on (the construction and execution of) REF, arguing that the proverbial 'Other' (Lacan, 1977) for who academic research is conducted ought not to be equated with the interests of individuals involved in REF panels:

We should be making a broader contribution. Actually, we need to be sensitive that if we want to make an impact, we have to do it on others' terms [than the terms of those involved in the REF]. [The REF] creates an imperative within institutions to build 
impact case studies, whereas we need to be doing these things on other people's terms. That creates a tension which I think is unhealthy.

UK P2 sought practitioner concerns to be heard and researched and, despite not supporting the prioritization of research performance and impact through REF, had decided to participate in the latter's consultation panels, even though the effects of their participation would likely be limited. They found the REF2021 system more reasonable than previous assessments, but they believed their opinion had insufficiently been taken into account, among others in relation to the brutality that they associated with particular REF requirements. This was expressed as follows by UK P2: "[We ought to find] a way of saying 'let's get rid of the myths that these journals are superior', because I know that there are still institutions where they use things like the ABS list to hit junior colleagues over the head".

One of those 'junior colleagues' (UK L2) literally felt some of the negative effects of managers aggressively demanding specific publications from junior staff (cf. Lorenz, 2012), and shared the following reflections:

[T] he problem for me is the power dynamics that go behind the three and four-star research, because it just equals a certain type of research in the eyes of certain people. I think the REF makes that dynamic a lot more powerful, because it systematizes and instrumentalizes power structures. Of course, the system will change over time, but I think [as an early career researcher] you're very much at the mercy of what those structures are, and how that feeds into job opportunities.

The proxies used by REF did not sit well with this particular academic, although they believed that measuring research performance could in principle be useful. They were concerned about the lack of focus on practitioner concerns, the stifling of creativity and innovation, and their own ability to change the rules. They had therefore joined the union, as well as several university committees to try and actively change their university's research policy and encourage greater pushback from academics on the power structures underlying REF (cf. Humphrey and Lukka, 2011).

UK SL5 expressed similar concerns about power structures as UK L2, but they had reached a very different conclusion. They deliberately “... stayed on a particular side of the line that gives me additional freedom. My contract is teaching and scholarship not teaching and research. [Assuming a changed contract] then you're very conscious that you're under the microscope of having certain number of publications in certain outlets." This participant, similar to many other UK participants, also believed that too much accounting research no longer focused on topics found relevant by practitioners (cf. Lowe and Tucker, 2014; Tilt, 2010; Tucker and Parker, 2014). They lamented other performative effects of REF as well:

One of the things that struck me when I first came into higher education was the essence of a collegiate culture where people were friendly and welcoming. ... I think that is not as good as it was. I see a lot of gaming [around me these days], and selfish behaviours. I think that drives the sorts of things that people research as well.

Similar views have been expressed by Humphrey and Lukka (2011) and, specifically for NZ, by Roa et al. (2009). UK SL5 found it hard to relate to these changes, despite their own publication record, and they were therefore considering leaving academia. In a recent, private conversation, they indicated that they would do so in 2020. They especially noted that individualism had grown in the accounting department of their university, despite the group type measurement underpinning REF. 
In NZ, a minority of the participants also continued to choose their own research path to a certain extent, in spite of the introduction of PBRF. Fetishism clearly was the dominant understanding of the spectacle among our interviewees there. Hence, NZ academics tended to be less critical than their UK colleagues about the disadvantages associated with PBRF. They therefore also gave fewer indications of active pushback.

Nevertheless, NZ SL3 noted several loopholes in PBRF, which accepts citations by others as a criterion to evaluate research outputs. They stated:

You know people cite themselves and you know those scores are increased. Personally, I get much more satisfaction if the regulator says 'Wow. This was a very interesting piece of work can we distribute it amongst ourselves' than me having $H$ - whatever impact score. That's personal satisfaction to me.

Therefore, while being negative about the ability of the PBRF to support creativity and innovation, NZ SL3 felt that practitioner concerns were important and they actually emphasized these in their research. Their statement shows that academics may consciously decide to follow their own path when it comes to determining what they perceive to be valuable research.

NZ SL4 indicated the following in relation to the measurement of research impact:

Research impact, [well] you [could] also look at the benefit of the research you've done to, the public eye or an interest group. The things I do, which are mainly in tax, may be beneficial especially to the tax department. This you sometimes cannot measure because they will not tell you that 'we use your stuff to do this'. Ideas might be generated from the work that you have done. I believe that tax research is an applied research, I think it is really useful for the government, and it's hard to measure because you're not automatically told that it has research impact. But they read my work.

NZ SL4 had therefore paid considerable attention to their personal contacts with the tax department, despite the fact that this would not typically be appreciated under currently prevailing PBRF requirements. They explained the way they chose research topics: "I dig deep in the area that I want to research rather than [the] PBRF ranking of journals." As to research quality, the following was said about the role of university management by NZ SL4: “... they have [been promoting] the H-index. I don't pay a lot of attention to it, although to the university it is important. But to me it doesn't mean a lot of things." Therefore, while positive about RA in a general sense, they were negative about the ability of the NZ system to enhance creativity and innovation. They also believed that since the introduction of PBRF, some academics were less willing to review papers for academic journals given the time this would take away from their own research. They also believed it was important that practitioner concerns kept on being addressed in research.

While there seemed to be genuine concerns about gaming the PBRF in NZ (cf. Curtis, 2007), and there were certainly also concerns about the ways in which research quality and research impact was assessed in PBRF, the only type of pushback we saw among a few of our interviewees was the greater emphasis they placed on practitioner concerns in their research. We conjecture that the focus on group assessment in the UK actually encouraged some academics to become more actively and openly involved in pushing back against its negative consequences, in the hope to gradually change the system so that it would become less powerful. However, none of these academics assumed that REF (or RA in general) would ever go away (cf. Lorenz, 2012) or needed to be rejected completely. Similar to Bogt and Scapens' (2012) conclusions in their study of Dutch and UK accounting academics, they seemed to see some 
benefits in RA exercises, as long as RA systems would be applied in specific (not too strict and/or generic) ways.

This ends our discussion of how accounting academics have related to REF and PBRF, from the viewpoint of RA as a spectacle. Of course, the views and excerpts we have presented are necessarily limited. They are also not exhaustive. However, they do shed what we perceive to be an insightful and partially novel light on the insights we have gathered from our interviews.

\subsection{Perceptions of difference}

We now analyse in greater detail the themes the interviewees explicitly addressed as they shared their experiences with REF and PBRF, following Flyverbom and Reineicke's (2017) classification. As stated in Section 4, our analysis focuses on whether and to what extent the themes in Section 2.3 were present in the interview accounts. Not everyone who submitted to REF, for example, may be expected to hold similar views on each and every theme. In Section 1 we argued why we assume there to be differences within the different RA systems, depending on who is asked. This is what we explore below.

Surprisingly, two themes that have been covered in the literature were not mentioned by any of our interviewees: (i) the effect of REF and PBRF on the amount of time researchers had (left or been granted) to conduct research; and (ii) the future of PhD and DBA programs. Hence, these themes were dropped from the analysis. However, we also found an additional theme, which we believe has not been frequently discussed in the literature to date: one's ability to adapt REF or PBRF rules and requirements so that they better fit one's own, or somebody else's, needs in terms of research activity. An example of this was provided in Section 5.3 when UK P2's involvement in REF consultation panels was addressed.

Using this refined set of themes, we investigated the positive and negative impressions that the interviewed accounting academics expressed about each of these, against the backdrop of Flyverbom and Reinecke's (2017) three understandings of the spectacle. This allowed us to compare and contrast the UK and NZ, and their respective RA systems, against the (modified set of) themes presented in Section 2.3. Since only one interviewee viewed REF as a hyperreality, we will solely focus on the other two understandings that Flyverbom and Reinecke set out.

\subsubsection{Fetishism}

The vast majority of the NZ and UK participants who submitted to REF and PBRF as a fetish acknowledged that RA had prioritized the impact of research. They generally believed this was a good thing, allowing greater reflection on their own research 'progress'. This contradicts many previous studies, which primarily emphasized the negative effects associated with a strong(er) emphasis on research measurement and assessment (e.g., Bogt and Scapens, 2012). It was the way of assessing research performance (impact) and its occasionally too strict operationalization that chiefly concerned these participants - if they made any comments on these matters. They expressed no concerns with the measurement of research performance itself.

Several of the NZ academics argued that PBRF spurred creativity in research, encouraging people to research and write things about topics they otherwise might not have. Again, this contradicts many other studies (e.g., Lorenz, 2012; Bogt and Scapens, 2012). The outcome may well be explained by these academics' fetishist tendencies. 
Some UK-based 'fetishists' addressed the 'game' that academic publishing had become after the introduction of REF. They actively participated therein - albeit in various ways. However, $\mathrm{NZ}$ academics offered few reflections on the 'game'. Perhaps they could not regard publication as a game given the prevalence of an individual system (PBRF) in their country. Especially to them, publishing in high-ranked journals might have become utterly real - an important and unavoidable given (see also Letiche, 2004).

At the same time, all of the NZ participants highlighted that PBRF encouraged individualism (one UK-based interviewee disagreed with this when they reflected on the differences between the REF and PBRF). Many NZ academics also suggested that, when designing new research projects, practitioners' concerns were not as important as they once had been. This confirms some of the inferences drawn in other studies (Humphrey and Lukka, 2011; Roa et al., 2009; Tucker and Parker, 2014). NZ academics were more vocal (and negative) than those in the UK about the exclusion of practitioner concerns in research, although they were fewer in numbers.

Both UK and NZ participants agreed that REF and PBRF were not being used very flexibly, but that they did not want to change the rules or requirements underlying them. Only a single NZ participant who unwittingly subscribed to a fetishist understanding of the spectacle did see room for future improvement of PBRF rules.

\subsubsection{Transformation}

Accounting academics who mainly saw PBRF and REF as a transformative mechanism were very mixed about how they perceived, in particular, PBRF's prioritization of specific types of research. Most of the NZ academics interviewed noticed a lack of creativity and innovation in research since the introduction PBRF. This very much confirms the results from previous studies (Agyemang and Broadbent, 2015; Murphy and Sage, 2014). Academics in both countries acknowledged that a greater focus on generating research outputs could be witnessed, in especially the last decade (cf. Lorenz, 2012). In this understanding of the spectacle, whilst there was some recognition in both countries that RA systems could be perceived as invoking a publication game, the reaction to this was mixed, with UK academics being mostly negative about the nature of the game and its consequences for especially junior academics. NZ academics tended to be less negative about the game, perhaps since they did not believe that RA would disappear quickly.

Especially some of the UK academics lamented the rigidity of REF, while NZ academics generally believed that PBRF could be used quite flexibly and could be adapted to suit one's own needs and interests. Academics in both countries stated that practitioner issues ought to be more important in REF/PBRF (Tucker and Parker, 2014), similar to the 'fetishists'. Some interviewees saw potential with the new prescriptions for impact case studies in REF for practitioner concerns to be valued.

Thus, although there is sameness within the differences that REF and PBRF bring about, there are interesting differences within the difference as well, which can partially be related to the view of the spectacle that interviewees endorsed. For example, the loss of creativity was barely emphasized in Section 5.4.1 (but it is in Section 5.4.2), whereas a desire to adapt REF/PBRF requirements is relevant in Section 5.4.2 (while mixed views were expressed in Section 5.4.1). These differences highlight that the behaviours exhibited by accounting academics in response to the presence of REF/PBRF are more fine-grained, and not as clear-cut, as has sometimes been proclaimed in the literature. In addition, views on RA (systems) among accounting academics in the UK generally seemed to be more negative than in NZ. Although our research 
did not explicitly focus on explaining this difference, we suggest various reasons why this may be the case. First, the impenetrable rating process applied in the 1986 RA exercise in the UK, which we briefly mentioned in Section 2.1 , was perceived very negatively by UK academics, although not all universities originally seemed to take this particular RA exercise seriously (Jump, 2013). It might be that this negativity, combined with a general tendency among UK academics to be sceptical of initiatives undertaken by the Thatcher, as well as by later conservative, governments set the tone for discussions about (future) RA ratings. Especially (older) academics at higher levels in the academic hierarchy criticised what was perceived to be the aggressiveness of REF measurements. In addition, it has been argued that the Thatcher government demolished a sense of collectivism and appreciation for pluralism (in research) that was then still present in UK (Albertson and Stepney, 2019). This is contrary to the situation in NZ, where depending on the ethnicity, collectivism still very much prevails (e.g., among people of Māori and Pasifika descent) and tertiary reforms were promulgated under a Labour, Conservative ('National') and then coalition government (Ministry of Education, n.d.). Hence, $\mathrm{NZ}$ academics might be somewhat more reserved in putting their individual stamp on things than UK academics (for example, when offering critique). Successive NZ governments have also been known not to make policy changes unless they have closely analysed others' responses to similar problems. Hence, they have tended to follow other nations' cues, as noted when we discussed the background of the PBRF introduction in Section 2.1. After the UK had introduced RA in 1986, NZ governments began discussing the needs for similar reforms (Ministry of Education, n.d.). The necessity of conducting RA may not have been questioned since. This may have influenced the attitude of NZ academics towards RA (in general) as well, which, in turn, may have been reflected in our interviews. However, it might also be that we happened to select more critical interviewees in the UK.

We thus find a mixture of advantages and disadvantages from increased RA in this study. Some of our interviewees managed to thrive and become more recognized within the accounting discipline as a consequence of the introduction of REF and PBRF, but some of them have been considering to leave academia as well, despite their active research agendas. It is important to note that the intrinsic motivation of (especially junior) academics might well be driven out when RA systems are applied (too) carelessly (cf. Bogt and Scapens, 2012; van der Kolk et al., 2015 ) - indications of which we have presented in Section 5.3 when we discussed, for instance, UK SL2's impressions of current university life. This we would personally find the most detrimental effect that RA systems can have on academia and academics.

\section{Discussion and conclusions}

While this research analysed a relatively small number of participants and therefore cannot be representative of all accounting academics across the UK and NZ, the selection of our particular cross-section of 19 academics from a number of universities, and across a number of hierarchical levels, enabled a rich data set that allowed us to study a variety of meaning-making processes about the role and content that these academics attribute to the research they do in the course and fostering of their career. We put the case that the variety of viewpoints found in this study is more extensive than can be seen in many other studies. The 'fetish', 'spectacle' and 'hyper-real' triad, derived in part from Debord (1992), worked as a heuristic to organize our data.

While personal effort is required in both jurisdictions, in the UK, academic research is chiefly assessed on a group basis. There are approximately 140 universities involved in the REF assessment, which may explain the latter's group focus. In NZ, assessment is primarily 
conducted on an individual basis, covering eight universities (along with other smaller tertiary institutes). Given its individual nature, NZ academics have no other option than to submit to PBRF. They generally were appreciative of many aspects of PBRF (specifically those at a higher level of appointment) and its consequences, except for the suppression of practitioner concerns. There was a lack of concern to change the 'rules', or perhaps merely an acceptance of the PBRF as is, as compared to the UK. However, some concerns were raised about the stifling of creativity in research that they had witnessed across accounting departments (cf. Bogt and Scapens, 2012; Lorenz, 2012).

In addition, all NZ participants indicated that they saw growing self-interestedness in academia as a consequence of the introduction of the PBRF, which may partially be attributed to the individual nature of the system (Humphrey and Lukka, 2011; Roa et al., 2009). This threatens the creation of collective knowledge through formal and informal conversation and sharing. Hence, this can be claimed to be a disadvantage of individual assessment processes academics may be confronted with. In NZ, another disadvantage seemed to hold for reviewing papers, which some academics were less willing to do, as it took too much time. Such concentration on oneself may be linked with a potentially much broader threat: assuming that others are content with the RA systems imposed upon them, and thinking that an RA system is therefore perfectly (or largely) in order or viable. This hinders the development of better RA systems in academia, and may lead to insufficient or insufficiently detailed discussions about how these might be established, effectuated, and changed. Thus, a paradoxical result of introducing RA systems in academia has emerged: not only can the individualization of outputs be witnessed (as could be expected), but also the implicit rejection of the university as a cohesive workplace. This may eventually tear research staff, and perhaps even universities in their entirety, apart if it is not acted upon quickly as individualization continues (Debord, 1992).

We find it striking that REF seemed to provide more opportunities for individual escape than PBRF. In the UK, there seemed to be a general recognition that the proxies used for research performance were just that - imperfect proxies or a spectacle. While one could hardly avoid RA, one could try to change it. The detrimental effects of excessively emphasizing particular proxies or performance criteria in the evaluations, particularly by university managers, worried UK academics, as did the increasing lack of emphasis in accounting on practitioners' concerns (cf. Tucker and Parker, 2014). According to these academics, research impact seemed more to refer to spectacle impact than practitioner impact.

Our analysis, which was mainly based on Flyverbom and Reinecke (2017), produced several questions as well. Debord (1992) was a moralist. For him, uncritical participation in a fetishized spectacle was demeaning and threatened to destroy one's humanity. Research thus had to be disinterested, responsive, and free of external control, otherwise it would just be intellectualized marketing for someone's self-interests. However, RA exercises do exactly that. This produces a tautological loop. How many of the accounting academics we interviewed simply were inside that loop, were willing or content to stay there, and based their responses to us thereon? Were they the 'victims' of spectacle or the willing participants in the REF/PBRF spectacle; and how would we ever know - except for the one academic who decided to leave academia as he had become too dismayed by what he had witnessed in his department? Debord asserts that there is an outside to every spectacle and that we should be morally committed to occupy that space. He refused institutional containment and insisted on the radical independence of thought of the researcher. The identification of 'truth' with individual thought and independence, however, is not part and parcel to the majority of our sample, but it is taken to the extreme by Debord. Researchers have individual responsibility and are accountable for their assumptions, research conduct and the methods they apply, but they are also social beings 
investigating shared circumstances and interactions. Each researcher and object of research is a particularity, but they are also meant to have shared significance and are assumed to support a common ground. Flyverbom and Reinecke's (2017) 'fetish', 'spectacle' and 'hyper-real' are important criteria for reflection; but the idea that there is space outside of the three positions would be doubtful. Do our data show that the spectacle is so pronounced that it no longer provokes grave criticism? Have we been 'spectacle-ized' to the point that Debord's (1992) critique about being independent no longer disturbs us? Or is there something fundamentally wrong in Debord's assumption of a norm of independent research and researchers? The problem we were faced with as we performed our analysis is that neither REF nor PBRF has really addressed the question of what is research. Pushing for more journal publications and dissemination may be considered to be a rather feeble excuse for a definition. In that respect, Debord may be right: the spectacle of research has become the new norm while the substance of doing research has been left abject.

There is also an issue related to Flyverbom and Reinecke (2017) and Debord (1992) that we left underexplored in Section 4. It may be claimed that research infused by fetishism aims to produce pragmatic advice and models of 'best practices'. Spectacle research tends to focus on sociological investigation and examining the role of organizations in society. Studies in hyperreality challenge relativism and suggest the possibility that 'anything goes' in organizations' operations. The first type of research (fetishism) lionizes the means to business success, the second questions the quality of relatedness in organization, and the third (hyper-reality) leads to radical doubt and indeterminacy. Fetishist research assumes that business and management studies (including accounting) should support the goals and performance of businesses; spectacle research should highlight the role of human relations in organizational life; and hyper-real research that we are all challenged by radical doubt. The three positions, on the one side, differ in how they configure their research goals; and on the other side they describe very different self-identities and forms of reflexivity. Thus, 'fetish', 'spectacle' and the 'hyper-real' are descriptors of ways of seeing both the objects of research and the role or identity of researchers. We have not explicitly looked at the former of these interpretations, but this could be explored further in other studies.

As RA systems are becoming an increasing feature of academics' lives across the world, further research is needed analyzing the manner(s) in which researchers perceive research, themselves, and the 'truth' generated and purported via these systems using other frameworks than the one(s) we have used in this paper. On top of this, we would argue that an agenda for change is needed in order to bring into focus the concerns of practitioners for relevant research, greater collaboration with and between accounting scholars (rather than self-interestedness) and more creativity. While it has been acknowledged that RA systems, and performance measurement systems in general will always be partial and are likely to prevail for an extensive period of time (Jack, 2017; Potter, 2005), as academics we can take responsibility to ensure that such systems reflect the future we wish to create. It is certainly not mainly or solely the role of upper management officials to set this in motion, or make this happen (Lorenz, 2012; Verhaeghe, 2014). More attention is demanded in this respect to the intricate relationships between researcher identity, research content and institutional arrangements. 


\section{Notes}

Obviously, difference and sameness go hand in hand. Hence, this topic will be addressed later as well.

Murphy and Sage's (2014) exploration of media coverage of REF-outcomes indicated that, while senior academics expressed concerns about academic freedom, junior academics and journalists mainly seemed to be concerned with research having sufficient 'impact'. REF was more negatively viewed by natural scientists than by researchers in other disciplines (e.g., the social sciences).

iii In New Zealand the ranking system generally used is the Australian Business Deans Council (ABDC) list, which rates journals from not-rated, through $\mathrm{C}$ to $\mathrm{A}$, and $\mathrm{A} *$ (DeVilliers and Hsaio, 2018). These authors find disparities between the measures ABS and ABDC apply to define quality, highlighting the subjectivity and inconsistencies involved in their determination.

iv Māori are New Zealand's indigenous people. 


\section{References}

Agyemang, G. and Broadbent, J. (2015), Management control systems and research management in universities. Accounting, Auditing \& Accountability Journal, Vol. 28 No. 7, pp. 1018-1046.

Albertson, K. and Stepney, P. (2019), 1979 and all that: a 40-year reassessment of Margaret Thatcher's legacy on her own terms, Cambridge Journal of Economics (bez037). Available at: https://doi.org/10.1093/cje/bez037

Alvesson, M. (2011), Interpreting interviews, Sage, London.

Baudrillard, J. (1981), Simularcra and simulation, University of Michigan Press, Ann Arbor.

Baudrillard, J. (1999), Fatal strategies, Pluto Press, London.

Baudrillard, J. (2001), Impossible exchange, Verso, London.

Bogt, H. J. Ter and Scapens, R.W. (2012), Performance management in universities: effects of the transition to more quantitative measurement systems. European Accounting Review, Vol. 21 No. 3, pp. 451-497.

Boiral, O. (2013), Sustainability reports as simulacra? A counter-account of A and A+ GRI reports. Accounting, Auditing \& Accountability Journal, Vol. 26 No. 7, pp. 1036-1071.

Bovens, M. (2005), Public accountability. In: Ferlie, E., Lynn, L.E. and Pollitt, C. Eds.).The Oxford Handbook of Public Management, Oxford University Press, Oxford, pp.182-208.

Buckle, R.A. and Creedy, J. (2018), The evolution of research quality in New Zealand universities as measured by the performance-based research fund process. New Zealand Economic Papers, pp.1-22.

Busco, C. and Quattrone, P. (2018), Performing business and social innovation through accounting inscriptions: an introduction. Accounting, Organizations \& Society, Vol. 67 No. 1, pp. 15-19.

Cederstrom, C. and Hoedemaekers, C. (2012), On dead dogs and unwritten jokes: life in the university today. Scandinavian Journal of Management, Vol. 28 No. 3, pp. 229-233.

Chua, W.F. (2019), Radical developments in accounting thought? Reflections on positivism, the impact of rankings and research diversity, Behavioral Research in Accounting, Vol. 31 No. 1, pp. 3-20.

Chwastiak, M. (2001), Taming the untamable: planning, programming and budgeting and the normalization of war. Accounting, Organizations \& Society, Vol. 26 No. 6, pp. 501-519.

Chwastiak, M. (2006), Rationality, performance measures and representations of reality: planning, programming and budgeting and the Vietnam war. Critical Perspectives on Accounting, Vol.17 No. 1, pp. 29-55.

Cooper, C. and Otley, D. (1998), The 1996 Research Assessment Exercise for business and management. British Journal of Management, Vol. 9 No. 2, pp. 73-89.

Covaleski, M.A.and Dirsmith, M.W. (1990), Dialectic tension, double reflexivity and the everyday accounting researcher: on using qualitative methods. Accounting, Organizations\& Society, Vol. 15 No. 6, pp. 543-573. 
Cunliffe, A.L., Luhman, J.T. and Boje, D.M. (2004), Narrative temporality: implications for organizational research. Organization Studies, Vol. 25 No. 2, pp. 261-286.

Curtis, B. (2007), Academic life: commodification, continuity, collegiality, confusion and the Performance Based Research Fund. New Zealand Journal of Employment Relations, Vol. 32 No. 2, pp. 1-16.

Curtis, B. and Matthewman, S. (2005), The managed university: the PBRF, its impacts, and staff attitudes. New Zealand Journal of Employment Relations, Vol. 30 No. 2, pp. 1-17.

Debord, G. (1992), The society of the spectacle, Rebel Press, London.

Denzin, N.K. (2014), Interpretive autoethnography, (2 ${ }^{\text {nd }}$ Ed.) Sage, London.

Department for the Economy, Higher Education Funding Council for Wales, Research England and Scottish Funding Council (2019), Guidance on submissions.(REF 2019/01, January, UK).

DeVilliers, C. and Hsiao, P.-C.K. (2018), A review of accounting research in Australasia, Accounting \& Finance, Vol. 58 No. 4, pp. 993-1026.

Ezzamel, M. (2012), Accounting and order, Routledge, London.

Flyverbom, M. and Reinecke, J. (2017), The spectacle and organization studies. Organization Studies, Vol. 38 No. 1, pp. 1625-1643.

Foucault, M. (1998), Aesthetics, method, and epistemology (Essential works of Foucault, 19541984, vol. 2), The New Press, New York

Frey, B.S. and Oberholzer-Gee, F. (1997), The cost of price incentives: an empirical analysis of motivation crowding-out. American Economic Review, Vol. 87 No. 4, pp. 746-755.

Goldfinch, S. (2003), Investing in excellence? The performance-based research fund and its implications for political science departments in New Zealand. Political Science, Vol.55 No. 1, pp. 39-53.

Green, M. (2019), Management scholarship and organisational change: representing Burns and Stalker, Routledge, London.

Hare, P.G. (2003), The United Kingdom's Research Assessment Exercise: impact on institutions, departments, individuals. Higher Education Management and Policy, Vol. 15 No. 2, pp. 43-62.

Humphrey, C. and Lukka, K. (2011). (AC)Counting research: the value of holistic understanding. In: Lee, B. and Cassell, C. (Eds.). Challenges and controversies in management research, Routledge, New York, pp. 174-195.

Jack. L. (2017), Accounting and social theory, Sage, London.

Jump, P. (2013), REF “contextual data" decision could enrich league tables, Times Higher Education, 3 December 2013. Available at: https://www.timeshighereducation.com/news/refcontextual-data-decision-could-enrich-league-tables/2009593 (accessed 29 January 2020).

Kallio, K., Kallio, T., Tienari, J. and Hyvonen, T. (2015), Ethos at stake: performance management and academic work in universities. Human Relations, Vol. 69 No. 3, pp. 685-709.

Kaufmann, V. (2006), The lessons of Guy Debord, October, Vol. 115, pp. 31-38 (Winter). 
Kaufmann, V. (2010), Revolution in the service of poetry, University of Minnesota Press, Minneapolis.

Kellard, N.M. and Sliwa, M. (2016), Business and management impact assessment in Research Excellence Framework 2014: analysis and reflection. British Journal of Management, Vol. 27 No. 4, pp. 693-711

Knights, D. and Clarke, C. (2014), It's a bittersweet symphony, this life: fragile academic selves and insecure identities at work. Organization Studies, Vol. 35 No. 3, pp. 335-357.

Kolk, van der, B., Bogt, H.J. Ter and van Veen-Dirks, P.M.G. (2015), Constraining and facilitating management control in times of austerity: case studies in four municipal departments. Accounting, Auditing \& Accountability Journal, Vol. 28 No. 6, pp. 934-965.

Lacan, J. (1977), Écrits: a selection, W.W. Norton \& Co, New York.

Lejeune, C., Davies, J. and Starkey, K. (2015), The impact of the impact agenda. Global focus: The EFMD Business Magazine, Vol. 9 No. 2, pp. 44-47.

Letiche, H. (2004), Baudrillard and organization, in: Linstead, S. (Ed.), Postmodernism \& organization, Sage, London, pp. 127-148.

Levinas, E. (1969), Totality and infinity: an essay on exteriority, Duquesne University Press, Pittsburgh.

Lorenz, C. (2012), If you're so smart, why are you under surveillance? Universities, neoliberalism, and New Public Management. Critical Inquiry, Vol. 38 No. 3, pp. 599-629.

Lowe, A. and Tucker, B.P. (2014), Practitioners are from Mars; academics are from Venus? An investigation of the research-practice gap in management accounting. Accounting, Auditing \& Accountability Journal, Vol. 27 No. 3, pp. 394-425.

Lowe, T. and Puxty, T. (1989), The problems of a paradigm: a critique of the prevailing orthodoxy in management control. In: Chua, W.F., Lowe, T., Puxty, T. (Eds.). Critical perspectives in management control, MacMillan Press, Basingstoke, pp. 9-26.

Lowrie, A. and Willmott, H. (2009), Accreditation sickness in the consumption of business education. Management Learning, Vol. 40 No. 4, pp. 411-420.

Macdonald, S. and Kam, J. (2007), Ring a ring 'o roses: quality journals and gamemanship in management studies. Journal of Management Studies, Vol. 44 No. 4, pp. 640-655.

Macintosh, N.B., Shearer, T., Thornton, D.B. and Welker, T. (2000), Accounting as simulacrum and hyperreality: perspectives on income and capital. Accounting, Organizations and Society, Vol. 25 No. 1, pp. 15-30.

Miller, P. and O'Leary, T. (1987), Accounting and the construction of the governable person. Accounting, Organizations \& Society, Vol. 12 No. 3, pp. 235-265.

Ministry of Education, (n.d.), "A history and Overview of the PBRF, Ministry f Education, Wellington. Available at: https://education.govt.nz/assets/Documents/Furthereducation/Policies-and-strategies/Performance-based-research-

fund/PBRFHistoryAndOverview.pdf.

Murphy, T. and Sage, D. (2014), Perceptions of the UK's Research Excellence Framework 2014: a media analysis. Journal of Higher Education Policy and Management, Vol. 36 No. 6, pp. 603-615. 
Northcott, D. and Linacre, S. (2010), Producing spaces for academic discourse: the impact of research assessment exercises and journal quality rankings. Australian Accounting Review, Vol. 20 No. 1, pp. 38-54.

Potter, B.N. (2005), Accounting as a social and institutional practice: perspectives to enrich our understanding of accounting change. Abacus, Vol. 41 No. 3, pp. 265-289.

Roa, T., Beggs, J.R., Williams, J. and Moller, H. (2009), Forum: New Zealand's Performance Based Research Funding (PBRF) model undermines Māori research. Journal of the Royal Society of New Zealand, Vol. 39 No. 4, pp. 233-238.

Salter, A., Salandra, R. and Walker, J. (2017), Exploring preferences for impact versus publications among UK business and management academics. Research Policy, Vol. 46 No. 10, pp. 1769-1782.

Tertiary Education Commission (TEC) (2004), Performance-based research fund. Evaluating research excellence: the 2003 assessment, Tertiary Education Commission, Wellington.

Tertiary Education Commission (2006), Performance-based research fund. Evaluating research excellence: the 2006 assessment, Tertiary Education Commission, Wellington.

Tertiary Education Commission (2012), Performance-based research fund. Evaluating research excellence: the 2012 assessment (final report), Tertiary Education Commission, Wellington.

Tertiary Education Commission (2018), Performance Based Research Fund. Available at: https://www.tec.govt.nz/funding/funding-and-performance/funding/fund-finder/performancebased-research-fund/ (accessed 14 November 2018).

Tilley, H., Ball, L. and Cassidy, C. (2018), Research Excellence Framework (REF) impact toolkit. Available at: https://www.odi.org/publications/11089-research-excellence-frameworkref-impact-toolkit (accessed 29 January 2020).

Tilt, C.A. (2010), The impact of academic accounting research on professional practice. In: Evans, E., Burritt, R. \& Guthrie, J. (Eds). Accounting education at the crossroads in 2010, Institute of Chartered Accountants in Australia, Sydney, pp. 59-68.

Tourish, D. and Willmott, H. (2015), In defiance of folly: journal rankings, mindless measures and the ABS Guide. Critical Perspectives on Accounting, Vol.26 No. 1, pp. 37-46.

Tucker, B.P. and Parker, L.D. (2014), In our ivory towers? The research-practice gap in management accounting. Accounting and Business Research, Vol. 44 No. 2, pp. 104-143.

Tucker, B.P., and Schaltegger, S. (2016), Comparing the research-practice gap in management accounting. Accounting, Auditing \& Accountability Journal, Vol. 29 No. 3, pp. 362-400.

Uddin, S., Gumb, B. and Kasumba, S. (2011). Trying to operationalise typologies of the spectacle. Accounting, Auditing \& Accountability Journal, Vol. 24 No. 3, pp. 288-314.

Verhaeghe, P. (2014), What about me? The struggle for identity in a market-based society, Scribe Publications, Melbourne.

Vollmer, H. (2007), How to do more with numbers: elementary stakes, framing, keying, and the three-dimensional character of numerical signs. Accounting, Organizations \& Society, Vol.32 No. 6, pp. 577-600. 
Vosselman, E.G.J. (2014), The 'performativity thesis' and its critics: towards a relational ontology of management accounting. Accounting and Business Research, Vol. 44 No. 2, pp. 181-203.

Willmott, H. (1995), Managing the academics: commodification and control in the development of university education in the UK. Human Relations, Vol.48 No. 9, pp. 993-1027.

Willmott, H. (2011), Journal list fetishism and the perversion of scholarship: reactivity and the ABS list. Organization, Vol. 18 No. 4, pp. 429-42.

Willmott, H. (2013) The substitution of one piece of nonsense for another. Journal of Management Studies, Vol. 50 No. 3, pp. 443-73. 
Table 1 Background information of interviewees.

\begin{tabular}{|l|l|l|l|l|}
\hline Position & Indicator & $\begin{array}{l}\text { University } \\
\text { number } \\
\text { (per } \\
\text { country) }\end{array}$ & $\begin{array}{l}\text { Interview } \\
\text { length (in } \\
\text { minutes) }\end{array}$ & $\begin{array}{l}\text { H-index } \\
\text { range }\end{array}$ \\
\hline New Zealand & & & & \\
\hline Lecturer & L1 & 3 & $41: 11$ & $1-5$ \\
\hline Lecturer & L2 & 1 & $22: 56$ & $6-10$ \\
\hline Senior Lecturer & SL1 & 2 & $49: 59$ & $10-15$ \\
\hline Senior Lecturer & SL2 & 1 & $19: 15$ & $1-5$ \\
\hline Senior Lecturer & SL3 & 5 & $35: 57$ & $1-5$ \\
\hline $\begin{array}{l}\text { Associate } \\
\text { Professor }\end{array}$ & SL4 & 1 & $18: 04$ & $10-15$ \\
\hline Professor & P1 & 4 & $25: 35$ & $15-20$ \\
\hline Professor & P2 & 5 & $30: 18$ & $15-20$ \\
\hline Professor & P3 & 6 & $47: 12$ & $15-20$ \\
\hline & & & & \\
\hline United Kingdom & & & & $62: 26$ \\
\hline Lecturer & L1 & 2 & $53: 25$ & $6-10$ \\
\hline Lecturer & L2 & 6 & $33: 24$ & $1-5$ \\
\hline Senior Lecturer & SL1 & 3 & $39: 22$ & $1-5$ \\
\hline Senior Lecturer & SL2 & 4 & $48: 08$ & $10-15$ \\
\hline Senior Lecturer & SL3 & 4 & $44: 28$ & $10-15$ \\
\hline Senior Lecturer & SL4 & 5 & $57: 54$ & $10-15$ \\
\hline Senior Lecturer & SL5 & 7 & $31: 02$ & $15-20$ \\
\hline Professor & P1 & 1 & $59: 44$ & $10-15$ \\
\hline Professor & P2 & 1 & $43: 09$ & $15-20$ \\
\hline Professor & P3 & & \\
\hline
\end{tabular}

